\title{
Community Pharmacists Knowledge of HIV/AIDS Management and Practice of Standard Precaution (A case study of Community Pharmacists in Abuja Municipal Area Council, Nigeria)
}

\author{
Article by Nnenna Genevieve Ekechukwu \\ Public Health, Texila American University \\ E-mail: nnennaekechukwu@gmail.com
}

\begin{abstract}
Background: In most communities, the first level of healthcare visit is usually the community pharmacies hence, has the chance to detect HIV for the provision of early intervention for HIV services. Consequently, if access to HIV care, treatment and prevention services is enhanced at the level of community pharmacies, the burden of HIV/AIDS in Nigeria will be reduced significantly.

Purpose: The study assessed the knowledge of community pharmacists regarding HIV/AIDS and its management and their level of standard precautions practice.

Methods: Out of 242 community pharmacists in Abuja Municipal Area Council (AMAC), Federal Capital Territory, a total of 155 registered community pharmacists who had valid practicing license were randomly selected. A questionnaire specifically designed for this study was self-administered to these participants. SPSS was used for the analysis, a P-value of less than 0.05 was regarded as significant and Chi-square tests were applied for inferential analysis.

Results: Within the 155 community pharmacists sampled, complete response were obtained from 104 (67\%) community pharmacists. The mean age of the participants was 44.3 years $(S D \pm 2.47)$. There were $72.1 \%$ males. $80.8 \%$ of the participants had only Bachelor of Pharmacy degree, $79.8 \%$ of participants reported correctly that HIV can be transmitted through with blood and semen and this was significantly associated with level of education ( $p=0.002)$. Most of the participants $(92.3 \%)$ did not know the HIV transmission rate from mother to child in the deficiency of antiretroviral drugs in developing countries and only $37.8 \%$ of community pharmacists keep stock of antiretroviral drugs for post exposure prophylaxis. Many of the participants (83.0\%) had good knowledge of the concept of standard precaution and $76.0 \%$ knew the conditions of which standard precautions should be practiced. $57.5 \%$ of the participants wash their hands with soap and water always after any direct contact with patients, 63.2\% recap used needles after giving injections or drawing blood from the patients. Only $26.9 \%$ had been vaccinated against Hepatitis $B$.

Conclusion: The finding of this study revealed that the knowledge and practice of community pharmacists in HIVIAIDS is relatively poor especially mother-to-child transmission. In as much as the knowledge of community pharmacists on standard precaution was good, there were paucities in their practice of standard precaution especially in the area of handling and disposal of used needles, poor availability of HIV post exposure prophylaxis drugs and vaccination against Hepatitis B. Management of HIV/AIDS should be integrated into the curriculum for continuing professional development for pharmacists. The implementation of adherence to the principles of standard precaution through consistent monitoring and supervision is highly recommended.
\end{abstract}

Keywords: Community pharmacists, knowledge and practices, HIV/AIDS \& standard precautions.

\section{Literature review}

Approximately about 36.9 million people were living with HIV globally as at 2017 (WHO 2018) and when compared with about 27.4 million in 2000, it can be deduced that there has been an incessant transmission of the virus despite a recorded improved access to antiretroviral drugs which have aided to 
reduce the mortality rate of the disease. HIV/AIDS has caused many deaths in Africa and is one of the main public health concerns in many African countries for example, Sub-Sahara Africa accounts for about two-thirds globally of people living with HIV. HIV spread made a quantum leap in Africa during the $20^{\text {th }}$ century due to urbanization, poverty, prostitution, education and health care (Van Niekerk A., Loretta MK., 2005). Nigeria being the second largest epidemic globally had about 3.2 million people living with HIV in 2016 (UNAIDS 2017) which affects all geographic areas and virtually all the population groups. Due to the healthcare providers to fight HIV epidemic both at the public health facilities and private health care facilities including the community pharmacies. Care and support are insufficient due to inadequate staff in terms of manpower and capacity.

Many healthcare providers have not had the necessary and satisfactory training on HIV prevention and treatment, and many healthcare facilities lack working materials, medications and equipment (Physicians for Human rights, 2006). Not all healthcare workers are knowledgeable of how HIV is transmitted (Aisien AO, 20 05). There are gaps in the knowledge of HIV by healthcare workers especially in their attitude and counselling practice and it is recommended very necessary that additional training be provided to them (Hentgen et al; 2002). Private Medical doctors owned up to having deficient knowledge, attitude and practice to PMTCT and $90.1 \%$ were willing to attend a capacity building course to update their knowledge (Okike et al; 2011). The knowledge, attitudes and practices of healthcare workers in HIV post exposure prophylaxis is high and the practice of wearing gloves during work activities was also high (Saoud et al;2013). The knowledge and practice of healthcare workers generally influence the quality of care provided to people living with HIV and their ability and willingness to access care (Dorothy Oqua $e t$ al 2011). Lack of proper training affect healthcare workers negatively on their work, stigma and shared confidentiality affect them emotionally. The need for speeded up training on HIV/AIDS of the rural nurses, a broader application of universal precautions and provision of post exposure prophylaxis in the public health facilities in South Africa were advocated for (Delobelle et al; 2009). Community pharmacies are possible outlet for improved access to HIV services since the community pharmacists dwell in the community among the people, interact with them daily and respected in the community (Micheal Thompson, 1999). Patients who are being provided medication therapy management by community pharmacists who have received intensive training on the management of HIV/AIDS such as adherence monitoring, adverse drug reaction identification and management, refill reminder services, rational use of drugs and referral when necessary for other medical services; have been found to be more adherent to their medication and better use of their medication (Hirsch et al; 2009).

Healthcare workers are often at risk of exposure to blood and other body fluids such as hepatitis B virus, hepatitis $\mathrm{C}$ virus and human immunodeficiency virus (HIV) during the course of their job (Shiao J. et al; 2002), therefore it is very crucial to prevent such exposure. Health workers ought to be vaccinated against hepatitis B to protect them and also their patients. Many healthcare workers fail to adhere to the practice of standard precaution (Garbus L. 2003, Mbanya DN. Et al 2001, Talashek ML. et al 2007). How much HIV transmission due to unsafe healthcare practices in Africa is debatable hence, eradicating every unsafe practice in health facilities ought to be a primacy for HIV prevention and for other infection control (Gisselquist D, Potterat JJ 2004, Schmid GP. et al; 2004). Occupational exposure can be due to needle stick, splash of blood into the eyes or blood contact with non-intact skin (Worker Health Chart book, 2004) seen as a serious problem and is a common cause of many disease transmission and mortality. All community pharmacy staff should be immunized against hepatitis B so that they do not get infected due to needle stick injury when accepting returned patient medicines due to returned lancets inside the bags of returned medicines (Pharmaceutical Journal, 2011).In some community pharmacies, clinical services such as immunization, blood glucose testing etc. are provided, thus staff can be exposed to accidental spillage of blood and body fluids when carrying out their activities e.g. provision of first aid (Pharmaceutical Journal, 2011).

Some pathogens transmitted from one person to other cause nosocomial infections through health workers who do not practice control measures such as hand disinfection, use of gloves etc. between 
patients (Horn WA. et al; 1988). A reduction of exposure risk to blood and body fluids has been demonstrated by compliance to principles of standard precaution (Chan R. et al; 2002). It is recommended that capacity building through continuing educational modules on hospital infection produces positive effect on adherence to infection control procedures and compliance to barrier techniques (Angelillo et al; 1999). Regular hand wash is a good way to prevent spread of common viruses and infections such as influenza and therefore should be encouraged. The knowledge and practice of standard precautions of healthcare workers in Federal Medical Center Asaba, Delta state Nigeria was found fair, however the need for further improvement through intensive healthcare training on various aspects of standard precautions and infection control programs was seriously recommended (Isara AR1, Ofili AN; 2010).

Adinma ED et al; 2009 examined the knowledge and practice, as well as factors influencing universal precautions practices amongst Nigerian House officers and nurses in tertiary health institutions in Southeast Nigeria and found that knowledge of universal precautions measures was high for both categories of respondents; $97.0 \%$ for doctors and $92.0 \%$ for nurses, although practice was better for nurses, $75.0 \%$, compared to the doctors, $15.2 \%, \mathrm{p}<0.05$. The study concluded that the effective knowledge and practice of universal precautions amongst hospital workers are very important to prevent infections from blood and body fluid pathogens. Hamid et al in their study of the knowledge of bloodborne infectious diseases and the practice of universal precautions amongst health workers in a tertiary hospital in Malaysia observed that there was a small positive correlation between knowledge and actual practice of universal precautions $(\mathrm{r}=0.3000, \mathrm{n}=206, \mathrm{p}<0.001)$ amongst the cohort studied. Factors such as age and years of experience did not contribute towards acquiring knowledge of blood-borne diseases or the practice of universal precautions. Compliance with non-recapping of usual needles was highest among trained nurses and worst with doctors (Sadoh WE. et al; 2006). A high percentage (94.6\%) of healthcare workers performed hand washing after handling patients while less than two-thirds of respondents (63.8\%) always used protective equipment.

Education has a positive impact on retention of knowledge, attitudes and practices among various categories of healthcare workers, compliance with interventions should be mandatory in order to reduce the incidence of nosocomial infections and there is a need to develop a system of continuous education for all level of healthcare workers (Suchitra and Lakshmi Devi, 2007).

\section{Mythology}

\section{Setting}

Abuja Municipal Area Councils was created on the $1^{\text {st }}$ October, 1984 and comprises of the following ethnic groups: Gbagyi, Gwandara, Koro, Gade, and Nigerians Spread across other ethnic groups. The Main Gbagyi settlement in AMAC includes: Karu, Nyanya, DurumiGarki, Ketti, Kabusa, Mabushi, Jabi, Lugbe, IdoToge, Hulumi, Pyakasa, Jikwoyi, Kurudu, OrozoMaitama and Asokoro areas. The Gwandaras are commonly found in Karshi, Nyanya, Sheretti, Gwagwa and Karmo areas. The rest of the population are distributed among these communities in pockets of settlements (Federal Capital Territory Area Councils Services Secretariat web portal, 2013).

The community Pharmacy is usually the first point of call for those in need of healthcare services, thus presenting opportunity for early intervention services such as referrals, treatment, counselling and palliative care. They are readily accessible $\&$ render affordable services. They have functional operational systems and a client base who have confidence in their person/practice \& hence willing to confide in them. The Community Pharmacists are respected community members of the communities located within the communities. They Are professional and competent and have long service hours (Usually open 8am9pm). The goals of this research are to ascertain the knowledge and practice of community pharmacists' in HIV/AIDS and standard precaution. 
DOI: 10.21522/TIJPH.2013.SE.19.01.Art016

ISSN: $2520-3134$

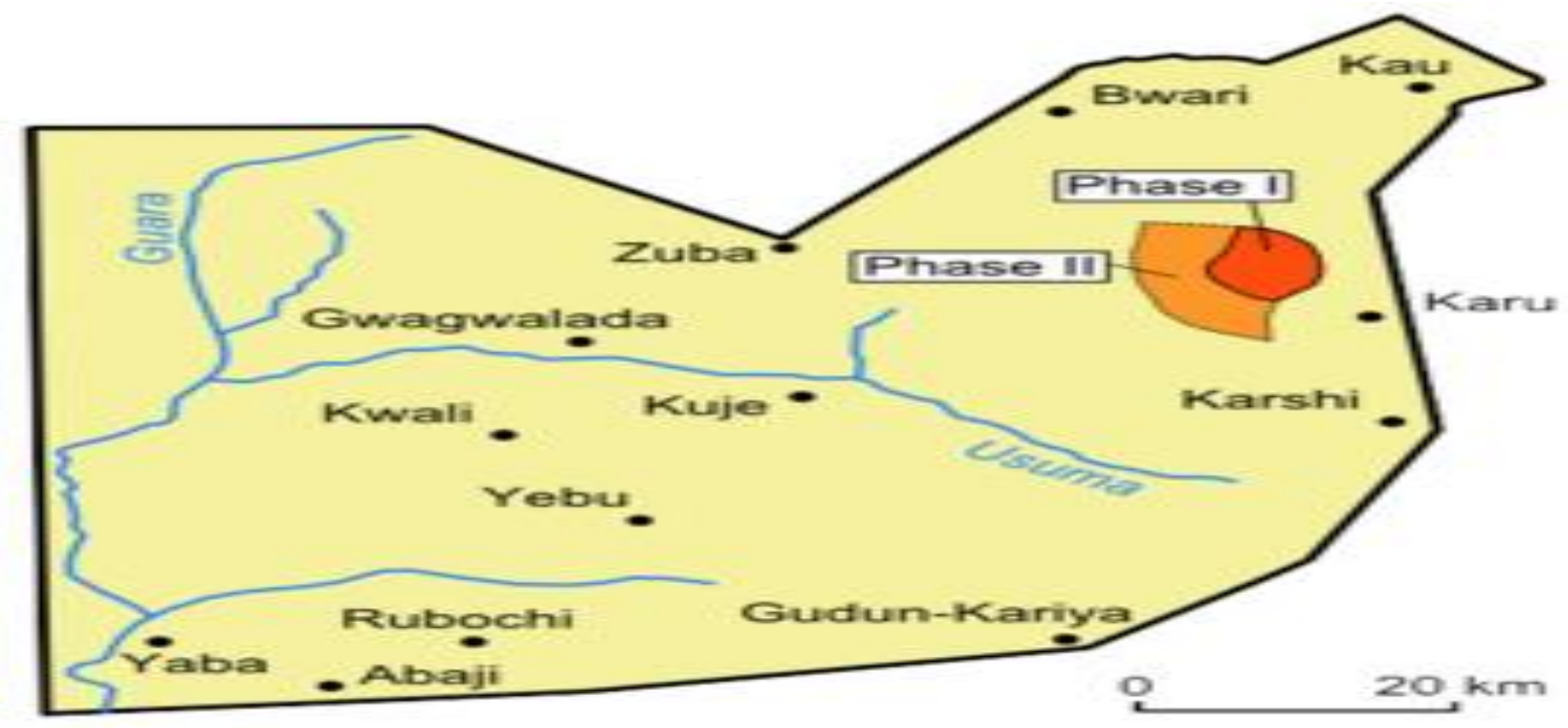

\section{Map of Abuja municipal council}

\section{Selection criteria}

Eligibility criteria to be included in the study are;

- Superintendent pharmacists in a community pharmacist located in AMAC.

- A valid practicing license

- You must be a registered community pharmacist

- Only pharmacists that consented to participate were included in the study.

Any patient who did not meet each of these criteria was excluded from the study.

\section{Study design}

This study is an analytical, cross-sectional study. The information was collected from the community pharmacists working in Abuja Municipal Area Council in FCT, Nigeria.

\section{Study population}

The study population included 242 registered community pharmacists in Abuja Municipal Area Council (AMAC) out of which 155 met the selection/inclusion criteria.

\section{Sample size calculation and sampling}

The sample size (n) was calculated as follows (Yamane, 1967):

$$
\mathrm{n}=\frac{\mathrm{N}}{1+\mathrm{N}(\mathrm{e})^{2}}
$$

Where $\mathrm{n}=$ the sample size; $\mathrm{N}=$ the study population $=242 ; e=$ the level of precision $( \pm 5 \%)$. Therefore,

$$
\mathrm{n}=\underbrace{242}_{1+242(0.05)^{2}}=150.8 \approx 151 \text { community pharmacists }
$$

The calculated sample size (n) was a total of 151 community pharmacists; however, the sample included 155 community pharmacists to accommodate for losses due to incomplete or missing data on 
important variables of interest. Out of the study population, 155 community pharmacists were selected using simple random technique.

\section{Ethical consideration}

Ethical approval for this study was obtained from FCT Health Research Ethics Committee (FHREC), Abuja Nigeria. Informed consent was obtained from the participants and confidentiality was assured by excluding identifiers during analysis.

\section{Reliability and validity}

Questionnaires were given to the experts in the field for content validity and were also pretested before they were administered.

\section{Data collection}

The pre-tested questionnaire was distributed to 155 community pharmacists. These pharmacists were randomly selected from a population of 242 community pharmacists located in AMAC. The questionnaires were self-administered and distributed to the pharmacies and also at the Association of Community Pharmacists in Nigeria, Abuja chapter forum, the pharmacists were given a deadline by which the completed questionnaires will be collected. The questionnaire consisted of 49 questions divided into 3 sections. Section 1 addressed demographic issues, section 2 addressed their knowledge and management practice of HIV/AIDS of which they were to choose A-E, while section three addressed their knowledge and practice of standard precaution of which they were to choose 1-5 and in some Yes or No.

\section{Data analysis}

To describe patient characteristics, proportions and medians were calculated. We compared proportions using chi-square tests. Chi-square was used to determine association between categorical variables and a P-value of less than 0.05 was considered significant. Data was presented in tabular and graphical forms.

\section{Results}

\section{Characteristics of participants}

A total of 104 community pharmacists were sampled in this study, $75(72.1 \%)$ were males and 29 (27.9\%) were females. Majority 80 (76.9\%) of the participants were aged 25-44 years, and only $6(5.8 \%)$ and $18(17.3 \%)$ were less than 25 years and greater than 44 years, respectively. The mean age of the participants studied was 32.88 years (standard deviation $(\mathrm{SD})=8.12$ ) and the mean year of experience at work was 4.43 years $(\mathrm{SD}=2.47) .26 .9 \%$ have been working for less than 1 year, $45.2 \%$ for $1-5$ years, $14.4 \%$ for $6-10$ years, $4.8 \%$ for $16-20$ years and $2.9 \%$ for $21-25$ years. Majority $84(80.8 \%)$ of the participants had only Bachelor of Pharmacy in their level of education, 7 (6.7\%) had Pharm D while 11 (10.6\%) had Master's degree. Of the participants, 74 (71.2\%) were fully employed and 27(26\%) were part time workers. The socio-demographic characteristics of the participants are summarized in [Table 1].

Table 1. Frequency distribution of socio-demographic characteristics of the participants; $\mathrm{N}=104$

\begin{tabular}{|l|l|l|}
\hline Characteristics & Frequency & Percent \\
\hline Sex & & \\
\hline Male & 75 & 72.1 \\
\hline Female & 29 & 27.9 \\
\hline Age group (years) & & \\
\hline $15--24$ & 6 & 5.8 \\
\hline $25-44$ & 80 & 76.9 \\
\hline $45-64$ & 18 & 17.3 \\
\hline
\end{tabular}


DOI: 10.21522/TIJPH.2013.SE.19.01.Art016

ISSN: 2520-3134

\begin{tabular}{|l|l|l|}
\hline 65 and above & 0 & 0.0 \\
\hline Level of Education & & \\
\hline B.Pharm & 84 & 80.8 \\
\hline Pharm D & 7 & 6.7 \\
\hline Masters & 11 & 10.6 \\
\hline PhD & 0 & 0.0 \\
\hline Not indicated & 2 & 1.9 \\
\hline $\begin{array}{l}\text { Status of } \\
\text { Employment }\end{array}$ & & \\
\hline Full Time & 74 & 71.2 \\
\hline Part-Time & 27 & 26.0 \\
\hline Not indicated & 3 & 2.9 \\
\hline $\begin{array}{l}\text { Length of time } \\
\text { with company }\end{array}$ & & \\
\hline$<1$ year & 28 & 26.9 \\
\hline $1-5$ years & 47 & 45.2 \\
\hline $6-10$ years & 15 & 14.4 \\
\hline $16-20$ years & 5 & 4.8 \\
\hline $21-25$ years & 3 & 2.9 \\
\hline Not indicated & 6 & 5.8 \\
\hline Religion & & 85.6 \\
\hline Christianity & 89 & 8.7 \\
\hline Islam & 9 & 5.8 \\
\hline Not indicated & 6 & \\
\hline
\end{tabular}

\section{Knowledge of community pharmacists regarding HIV/AIDS}

All participants reported correctly that HIV/AIDS is a contagious disease caused by virus. The knowledge of the causative agent of HIV was not associated with educational status and years of professional experience of the participants $(\mathrm{p}>0.05)$.

Of the participants, $83(79.8 \%)$ of them reported correctly that HIV can be transmitted through direct contact with blood and semen. The participants' knowledge of HIV transmission through contact with blood and semen was significantly associated with level of education $(\mathrm{p}=0.002)$. Of the participants, 68 $(81.9 \%)$ of them with only B. Pharm degree reported correctly that HIV is transmitted through direct contact with blood and semen compared to $4(57.1 \%)$ of those with PharmD degree and $11(100 \%)$ of those with Master's degree.

The years of professional experience of the participants was not significantly associated with knowledge of HIV transmission through contact with blood and semen $(\mathrm{p}=0.053)$. Of the participants who had < 1-year professional experience, 23 (82.1\%) were correct about HIV transmission through contact with blood and semen compared to $34(72.3 \%)$ for $1-5$ years, 15 (100.0\%) for 6 - 10 years, 5 $(100.0 \%)$ for $16-20$ years and $3(100.0 \%)$ for $21-25$ years.

Majority of the participants indicated correctly that HIV can be transmitted through sharing of razor blades [Figure 1]. The differences in knowledge of this mode of transmission by participants' level of education was not statistically significant $(\mathrm{p}=0.299)$ unlike the participants' years of professional experience $(\mathrm{p}=0.016)$. All participants who had 6-10 and 21-25 years of professional experience indicated correctly that HIV can be transmitted through sharing of razor blades compared to $93.6 \%$ for $1-$ 5 years of experience and $60.0 \%$ for $16-20$ years of experience. 


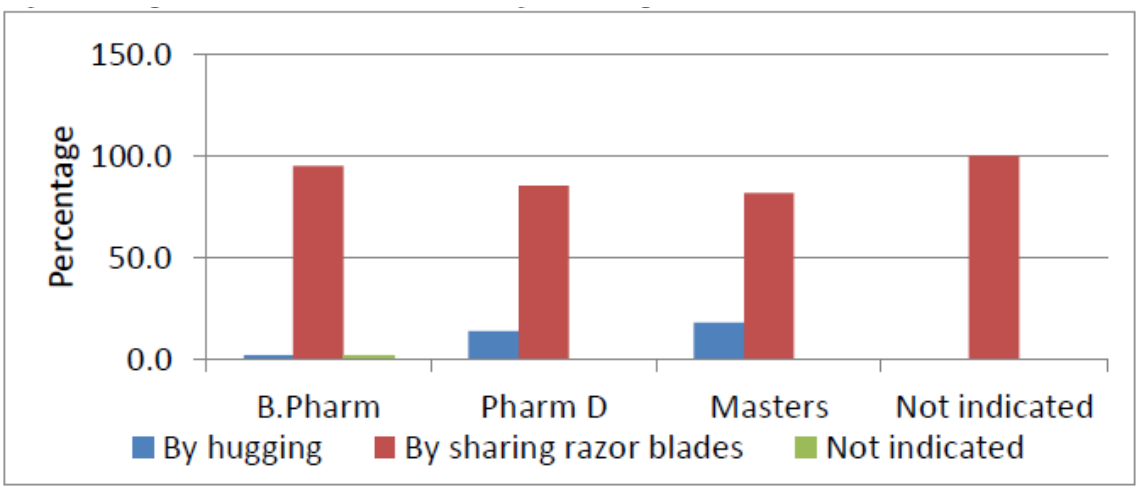

Figure 1. Frequency distribution of participants responses to routes of HIV transmission disaggregated by level of education, $\mathrm{N}=104$

Of the participants $93(89 \%)$ reported correctly that staying healthy by eating nutritious food is not a preventive measure to HIV infection [Figure 2].

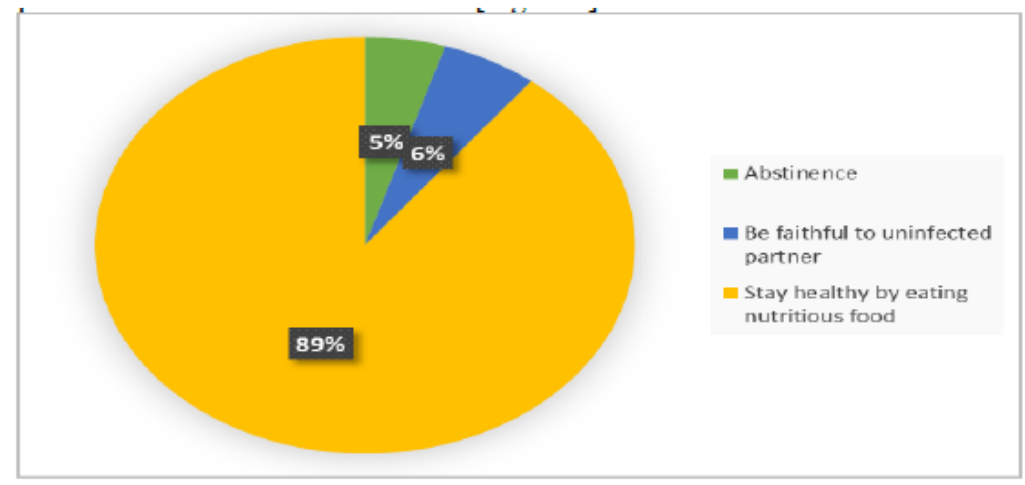

Figure 2. Frequency distribution of non-preventive measures for HIV infection as indicated by the participants; $\mathrm{N}=$ 104

Majority of participants (92.3\%) did not know that the HIV transmission rate from mother to child in the absence of antiretroviral drugs in developing countries was $25-35 \%$. The lack of knowledge about this was associated with participants' level of education $(\mathrm{p}=0.001)$ and years of experience $(\mathrm{p}=0.000)$. Of the participants who had B. Pharm, 92.9\% did not know HIV transmission rate from mother to child in the absence of antiretroviral drugs in developing countries, compared to $57.1 \%$ for Pharm D and $100 \%$ for participants who had Master's degree. Of the participants who had $<1$ year of professional experience, 80.8\% did not know HIV transmission rate from mother to child in the absence of antiretroviral drugs in developing countries, compared to $100 \%$ for $1-5$ years, $75 \%$ for $6-10$ years, $100 \%$ for $16-20$ years and $100 \%$ for participants who had 21-25 years of professional experience.

Majority of the participants $(91.5 \%)$ indicated correctly that Tuberculosis is the most common opportunistic infection in HIV-infected patients [Figure 3]. 
DOI: 10.21522/TIJPH.2013.SE.19.01.Art016

ISSN: $2520-3134$

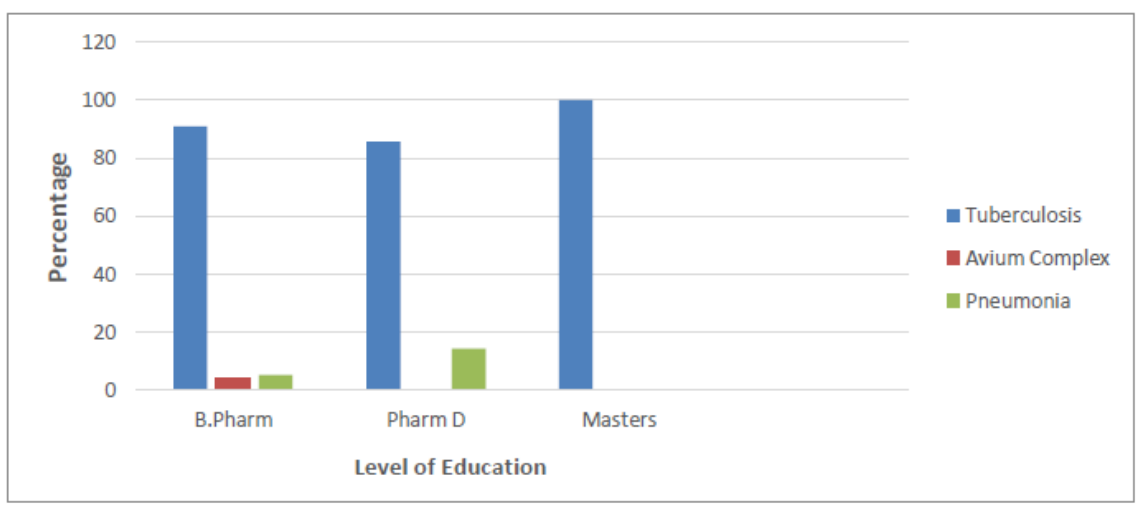

Figure 3. Frequency distribution of the most common opportunistic infection in HIV-infected patients as indicated by participants disaggregated by level of education, $\mathrm{N}=104$

Majority of participants (79.8\%) did not know that the chief predictor of heterosexual transmission of HIV is plasma viremia. Of the participants who had B. Pharm, $78.9 \%$ did not know that the chief predictor of heterosexual transmission of HIV is plasma viremia, compared to $85.7 \%$ for Pharm D and $63.6 \%$ for participants who had Master's degree. Of the participants who had <1 year of professional experience, $80.9 \%$ did not know that the chief predictor of heterosexual transmission of HIV is plasma viremia, compared to $80 \%$ for $1-5$ years, $66.7 \%$ for $6-10$ years, $100 \%$ for $16-20$ years and $100 \%$ for participants who had 21-25 years of professional experience.

\section{HIV Related Services Practiced at Community Pharmacies}

All CPs sampled had visibly placed valid practicing license issued by the Pharmacists Council of Nigeria and a pharmacist to supervise the dispensing of drugs as required by law. Of the CPs, only $77.7 \%$ had patient counseling area with audio and visual privacy; and $49.0 \%$ reported that they provide services to HIV infected clients. Only $37.8 \%$ of CPs in this study reported stocking antiretroviral drugs; and 47.9 $\%$ of them had records of the patient medication profile. Of the community pharmacists, only $63.2 \%$ were trained in Pharmaceutical Care in HIV/AIDS, TB and STI.

The common HIV related services provided at the community pharmacies were HIV risk assessment and counseling for clients (43.6\%) and palliative care services (72.1\%) - Table 2. Other common services provided at the community pharmacies included malaria prevention (91.7\%), STI treatment (93.8\%), provision of condoms $(92.5 \%)$ and referral services $(94.9 \%)$. The HIV related Services provided at Community Pharmacies are summarized in [Table 2].

Table 2. Frequency distribution of HIV related Services provided at Community Pharmacies

\begin{tabular}{|l|l|l|l|}
\hline Question Items & Yes (\%) & No (\%) & Total, N (\%) \\
\hline HTC SERVICES & & & \\
\hline $\begin{array}{l}\text { Does the pharmacist do HIV Risk Assessment \& } \\
\text { counseling for his clients? }\end{array}$ & $41(43.6)$ & $53(56.4)$ & $94(90.4)$ \\
\hline $\begin{array}{l}\text { Does the pharmacist provide HIV testing \& } \\
\text { counseling services? }\end{array}$ & $11(15.1)$ & $62(84.9)$ & $73(70.2)$ \\
\hline TB SERVICES & & & \\
\hline Does the pharmacist provide TB services? & $29(34.5)$ & $55(65.5)$ & $84(80.8)$ \\
\hline Does the pharmacist provide TB Screening? & $7(13.7)$ & $44(86.3)$ & $51(49.0)$ \\
\hline $\begin{array}{l}\text { Does the pharmacist provide TB Adherence } \\
\text { Support? }\end{array}$ & $7(13.7)$ & $44(86.3)$ & $51(49.0)$ \\
\hline Does the pharmacist provide TB Drugs Refills? & $19(32.8)$ & $39(67.2)$ & $58(55.8)$ \\
\hline Does the pharmacist provide DOTs/Community & $7(14.3)$ & $42(85.7)$ & $49(47.1)$ \\
\hline
\end{tabular}


Texila International Journal of Public Health Special Edition Apr 2019

\begin{tabular}{|c|c|c|c|}
\hline \multirow{2}{*}{\multicolumn{4}{|c|}{$\begin{array}{l}\text { TB Care? } \\
\text { PALLIATIVE CARE SERVICES }\end{array}$}} \\
\hline & & & \\
\hline $\begin{array}{l}\text { Does the pharmacist provide palliative care } \\
\text { services to PLHIV? }\end{array}$ & $62(72.1)$ & $24(27.9)$ & $86(82.7)$ \\
\hline $\begin{array}{l}\text { Does the pharmacist provide Adherence } \\
\text { Counseling to PLHIV? }\end{array}$ & $45(71.4)$ & $18(28.6)$ & $63(60.6)$ \\
\hline $\begin{array}{l}\text { Does the pharmacist provide OI management to } \\
\text { PLHIV? }\end{array}$ & $34(52.3)$ & $31(47.7)$ & $65(62.5)$ \\
\hline $\begin{array}{l}\text { Does the pharmacist provide Psychosocial } \\
\text { support to PLHIV? }\end{array}$ & $43(67.2)$ & $21(32.8)$ & $64(61.5)$ \\
\hline $\begin{array}{l}\text { Does the pharmacist provide Pain Management to } \\
\text { PLHIV? }\end{array}$ & $43(69.4)$ & $19(30.6)$ & $62(59.6)$ \\
\hline $\begin{array}{l}\text { Does the pharmacist provide Nutritional Support } \\
\text { and Counseling to PLHIV? }\end{array}$ & $43(69.4)$ & $19(30.6)$ & $62(59.6)$ \\
\hline \multicolumn{4}{|l|}{ MALARIA SERVICES } \\
\hline $\begin{array}{l}\text { Does the pharmacist provide Malaria Prevention } \\
\text { to PLHIV? }\end{array}$ & $50(91.7)$ & $16(8.3)$ & $66(63.5)$ \\
\hline $\begin{array}{l}\text { Does the pharmacist provide Malaria Treatment } \\
\text { to PLHIV? }\end{array}$ & $53(76.8)$ & $16(23.2)$ & $69(66.4)$ \\
\hline \multicolumn{4}{|l|}{ STI SERVICES } \\
\hline Does the pharmacist provide STI services? & 77 (84.6) & $14(15.4)$ & $91(87.5)$ \\
\hline Does the pharmacist provide STI Screening? & $19(30.6)$ & $43(69.4)$ & $62(59.6)$ \\
\hline Does the pharmacist provide STI Treatment? & $76(93.8)$ & $5(6.2)$ & $81(77.9)$ \\
\hline Does the pharmacist provide STI Counseling? & $79(91.9)$ & $7(8.1)$ & $86(82.7)$ \\
\hline \multicolumn{4}{|l|}{ RH/FP SERVICES } \\
\hline Does the pharmacist provide RH/FP services? & 77 (89.5) & $9(10.5)$ & $86(82.7)$ \\
\hline Does the pharmacist provide Condoms? & $74(92.5)$ & $6(7.5)$ & $80(76.9)$ \\
\hline $\begin{array}{l}\text { Does the pharmacist provide Emergency } \\
\text { Contraceptive? }\end{array}$ & $65(86.7)$ & $10(13.3)$ & $75(72.1)$ \\
\hline $\begin{array}{l}\text { Does the pharmacist provide Injectable } \\
\text { Contraceptives? }\end{array}$ & $67(82.7)$ & $14(17.3)$ & $81(77.9)$ \\
\hline $\begin{array}{l}\text { Does the pharmacist provide Oral Contraceptives } \\
\text { Provided? }\end{array}$ & $69(89.6)$ & $8(10.4)$ & $77(74.0)$ \\
\hline $\begin{array}{l}\text { Does the pharmacist provide } \mathrm{RH} / \mathrm{FP} \text { Counseling } \\
\text { services? }\end{array}$ & $55(78.6)$ & $15(21.4)$ & $70(67.3)$ \\
\hline \multicolumn{4}{|l|}{ REFERRAL SERVICES } \\
\hline Does the Pharmacist provide Referral Services? & $75(94.9)$ & $4(5.1)$ & $79(76.0)$ \\
\hline $\begin{array}{l}\text { Do you call on or refer client to a pharmacy for } \\
\text { HIV drugs? }\end{array}$ & $12(28.6)$ & $30(71.4)$ & $42(40.4)$ \\
\hline $\begin{array}{l}\text { Do you refer clients to a nearby Primary health } \\
\text { care for HIV services? }\end{array}$ & $14(66.6)$ & $8(36.4)$ & $22(21.2)$ \\
\hline $\begin{array}{l}\text { Do you refer clients to a tertiary hospital for HIV } \\
\text { services? }\end{array}$ & 37 (94.9) & $2(5.1)$ & $39(37.5)$ \\
\hline
\end{tabular}

The knowledge of standard precaution by community pharmacists

Majority of participants (83.0\%) had good knowledge of the concept of standard precaution. There was significant differences in knowledge by level of education $(\mathrm{P}=0.000)$ and years of professional 
DOI: 10.21522/TIJPH.2013.SE.19.01.Art016

ISSN: 2520-3134

experience $(\mathrm{p}=0.000)$. Of the participants who had B. Pharm, $88.2 \%$ had very good knowledge of standard precaution concept, compared to $57.1 \%$ for Pharm D and $77.8 \%$ for participants who had Master's degree. Of the participants who had $<1$ year of professional experience, $76.2 \%$ had very good knowledge of standard precaution concept, compared to $95.7 \%$ for $1-5 y e a r s, 66.7 \%$ for $6-10$ years and $60 \%$ for $16-20$ years.

\section{What are potential ways of occupational exposure?}

Of the participants $56(59.0 \%)$ indicated correctly all the potential ways of occupational exposure [Figure 4]. The knowledge of potential ways of occupational exposure was associated with participants' level of education $(\mathrm{p}=0.000)$ and years of experience $(\mathrm{p}=0.000)$. Of the participants who had $\mathrm{B}$. Pharm, $49(63.6 \%) \%$ ) indicated correctly all the potential ways of occupational exposure, compared to $0(0.0 \%)$ for Pharm D and 7(77.8\%) for participants who had Master's degree. Of the participants who had $<1$ year of professional experience, $38.5 \% \%$ ) indicated correctly all the potential ways of occupational exposure, compared to $33(70.2 \%)$ for $1-5 y e a r s, 5(50 \%)$ for $6-10$ years, $5(100 \%)$ for $16-20$ years and $0 \%$ for participants who had 21-25 years of professional experience.

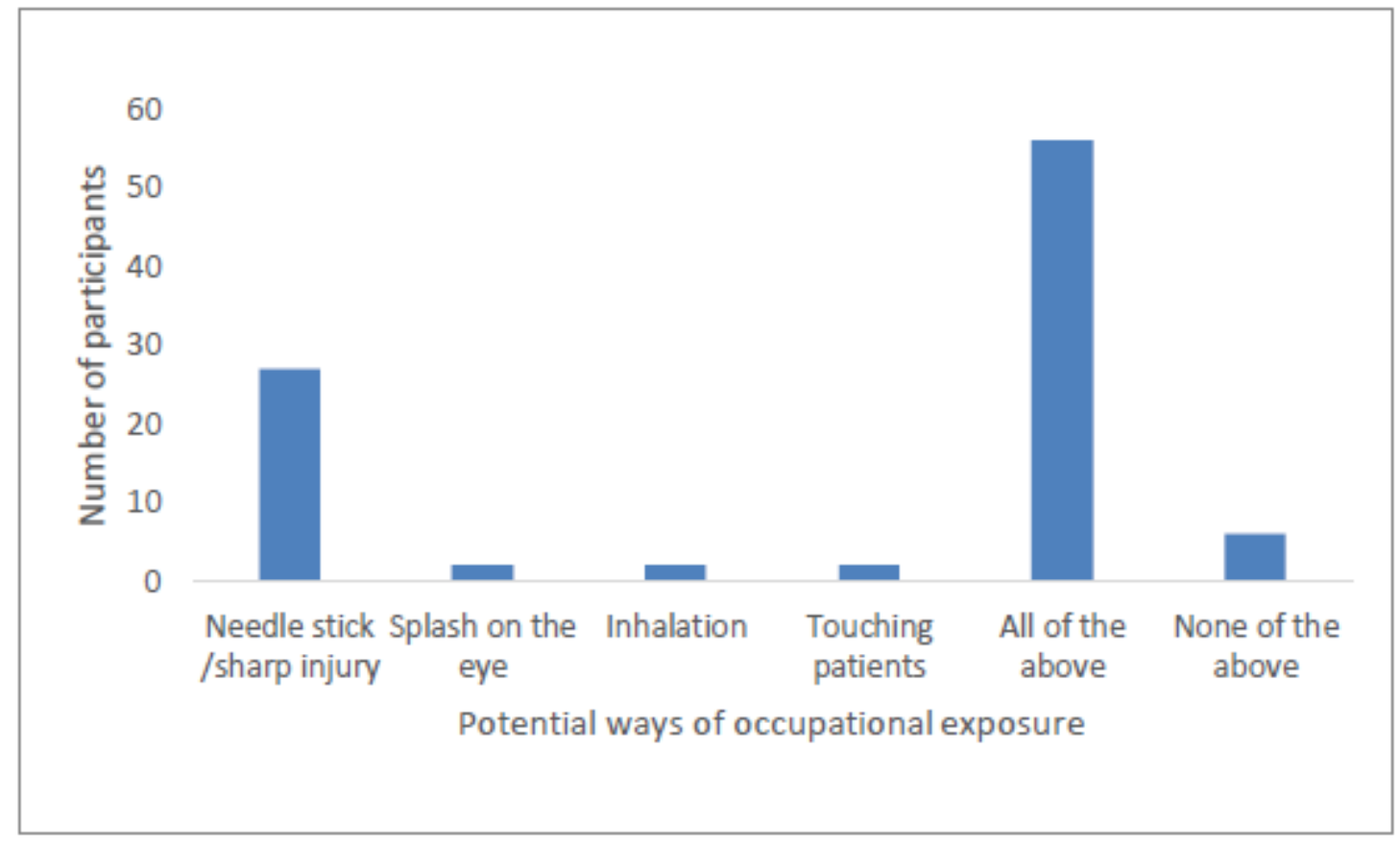

Figure 4. Frequency distribution of potential ways of occupational exposure, $\mathrm{N}=104$

\section{According to the standards precautions, hand washing is performed?}

Knowledge of Standard precaution of when hand washing is performed was significantly associated with the level of education $(\mathrm{p}=0.016)$ and years of professional experience of the participants $(\mathrm{p}=$ $0.000)$.). Of the participants, $54(73.0 \%)$ of them with only B. Pharm degree reported correctly when hand washing is performed compared to $1(25.0 \%)$ of those with PharmD degree and $4(44.4 \%)$ of those with Master's degree.

Of the participants who had < 1-year professional experience, $14(60.9 \%)$ were correct about when hand washing is perfomed compared to $36(80.0 \%)$ for $1-5$ years, $6(46.2 \%)$ for $6-10$ years, $5(100.0 \%)$ for $16-20$ years and $0(0.0 \%)$ for $21-25$ years.

\section{For which of these conditions should standard precautions be followed?}


Majority of participants $73(76.0 \%)$ reported correctly the conditions of which standard precautions should be practiced (Figure 5). The knowledge of the conditions of which standard precautions should be practiced was statistically associated with educational status $(\mathrm{p}=0.031)$ and years of professional experience of the participants $(\mathrm{p}=0.002)$.

Of the participants, 63 (79.7\%) of them with only B. Pharm degree reported correctly the conditions of which standard precautions should be practiced compared to $1(25.0 \%)$ of those with PharmD degree and $7(63.6 \%)$ of those with Master's degree.

Of the participants who had < 1-year professional experience, $16(64.0 \%)$ were correct about conditions of which standard precautions should be practiced compared to $38(80.6 \%)$ for $1-5$ years, 13 $(61.5 \%)$ for $6-10$ years, $5(100.0 \%)$ for $16-20$ years and $3(100.0 \%)$ for $21-25$ years.

\section{Which of the following body fluids require standard precautions?}

Of the participants $90(95.7 \%)$ reported correctly that blood, vaginal fluid, blood tinged body fluids and Saliva in dental procedures require standard precautions - Figure 5.

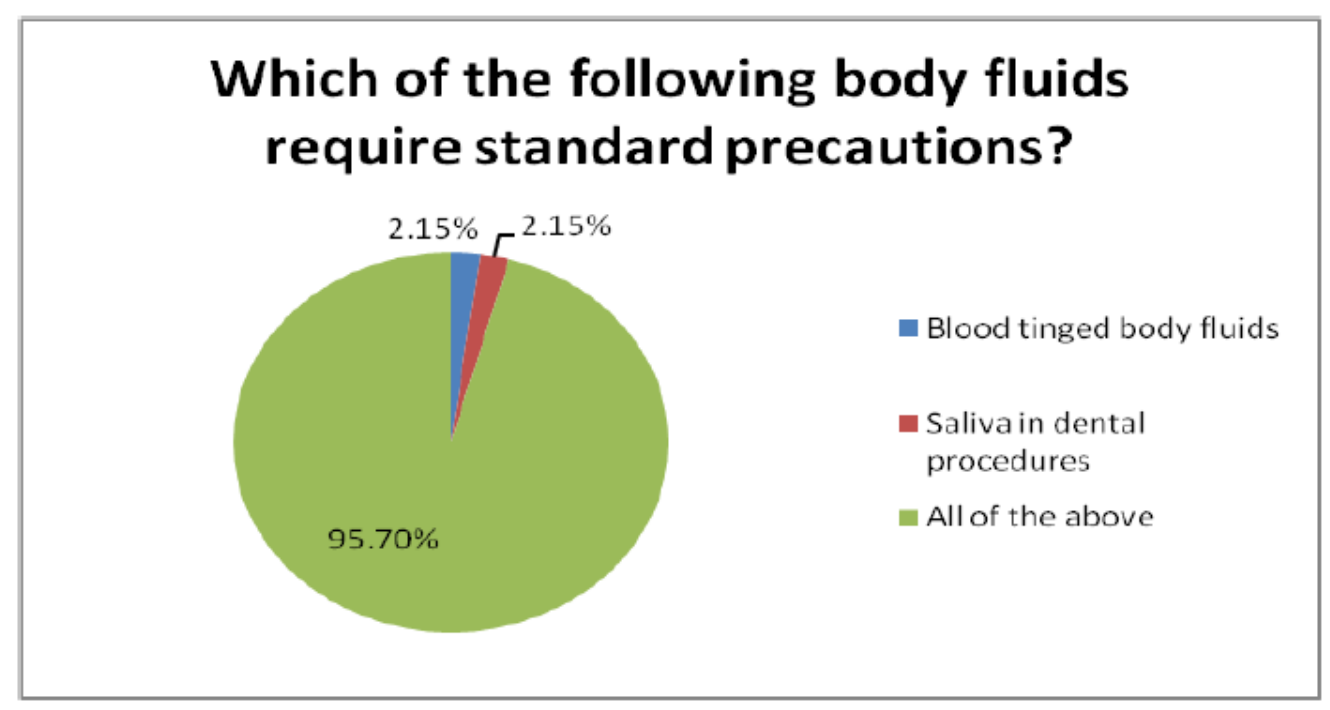

Figure 5. Frequency distribution of participants' responses to body fluids that require standard precautions disaggregated by level of education, $\mathrm{N}=104$

For HIV post exposure prophylaxis (PEP), HIV counseling \& testing is done immediately after the exposure and PEP is given only to HIV negative test result

The differences in the knowledge of standard precaution is not statistically significant in their level of education $(\mathrm{p}=0.392)$ but was significant in their length of professional experience $(\mathrm{p}=0.000)$. Of the participants, $31(45.6 \%)$ of them with only B. Pharm degree reported correctly that for HIV post exposure prophylaxis (PEP), HIV counseling \& testing is done immediately after the exposure and PEP is given only to HIV negative test result conditions of which standard precautions should be practiced compared to $3(75.0 \%)$ of those with Pharm D degree and 5 (55.6\%) of those with Master's degree.

Of the participants who had < 1 year professional experience, $12(52.2 \%)$ were correct about HIV post exposure prophylaxis (PEP), HIV counseling \& testing is done immediately after the exposure and PEP is given only to HIV negative test result compared to $18(41.9 \%)$ for $1-5$ years, $6(54.6 \%)$ for 6 - 10 years, $0(0.0 \%)$ for $16-20$ years and $3(100.0 \%)$ for $21-25$ years.

Two or three antiretroviral drugs are given immediately after the exposure but within 72 hours 
DOI: 10.21522/TIJPH.2013.SE.19.01.Art016

ISSN: $2520-3134$

Majority of participants $71(88.8 \%)$ reported correctly that two or three antiretroviral drugs are given immediately after the exposure to HIV but within 72 hours (Figure 6). The knowledge of when post exposure prophylaxis should be given was statistically associated with educational status $(\mathrm{p}=0.050)$ and years of professional experience of the participants $(\mathrm{p}=0.000)$.

Of the participants, $58(89.2 \%)$ of them with only B. Pharm degree reported correctly the conditions of which standard precautions should be practiced compared to $4(57.1 \%)$ of those with PharmD degree and $9(81.8 \%)$ of those with Master's degree.

Of the participants who had < 1-year professional experience, $16(76.2 \%)$ were correct about conditions of which standard precautions should be practiced compared to $41(95.3 \%)$ for $1-5$ years, 11 $(100.0 \%)$ for $6-10$ years, $0(0.0 \%)$ for $16-20$ years and $3(100.0 \%)$ for $21-25$ years.

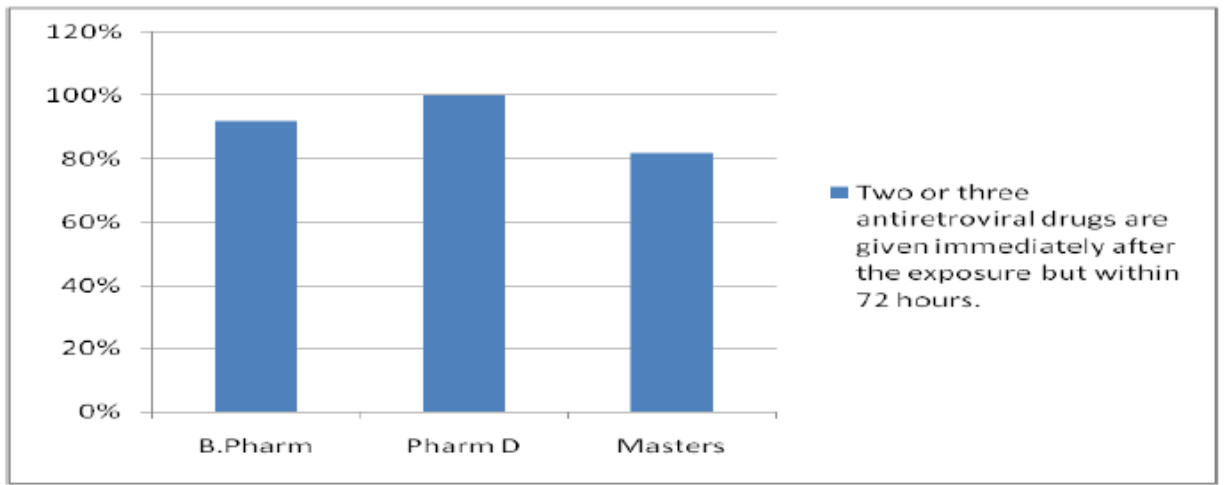

Figure 6. Frequency distribution of participants correct responses to standard precaution practices to HIV post exposure disaggregated by level of education, $\mathrm{N}=104$

\section{Antiretroviral drug is taken for 4 weeks}

Majority of participants $59(83.1 \%)$ reported correctly that antiretroviral drug is taken for 4 weeks Figure 7. The differences in knowledge of precaution by participants' level of education was statistically significant $(\mathrm{p}=0.014)$ unlike the participants' years of professional experience $(\mathrm{p}=0.000)$. All participants who had 16 -20 years and 21-25 years of professional experience indicated correctly that antiretroviral drug is taken for 4 weeks for post exposure prophylaxis to HIV compared to $68.8 \%$ for $1-5$ years of experience and $66.7 \%$ for $6-10$ years of experience.

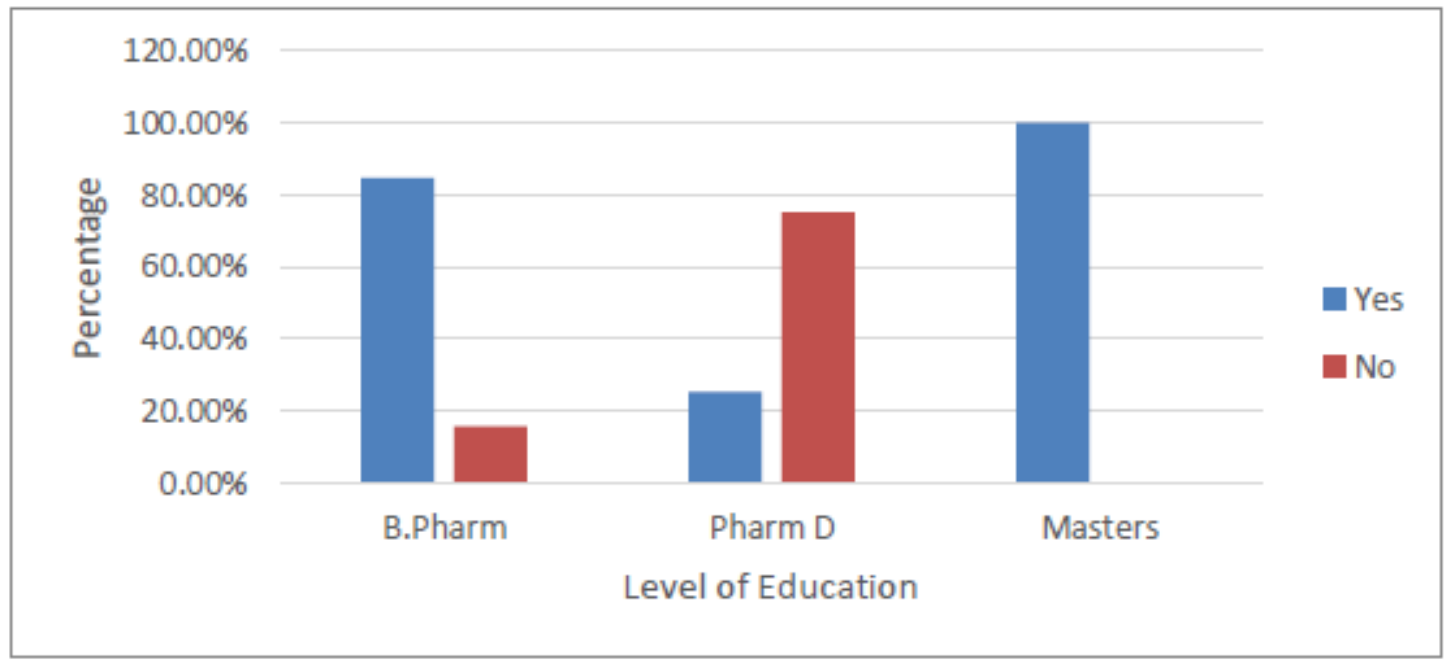

Figure 7. Frequency distribution of participants' responses to whether antiretroviral drug is taken for 4 weeks disaggregated by level of education, $\mathrm{N}=104$ 


\section{The practice of standard precaution by community pharmacists}

Majority of the participants wash their hands with soap and water always after any direct contact with patients $50(57.5 \%)$, while $26(29.9 \%)$ often wash their hands with soap and water after any direct contact with patients, and $11(12.6 \%)$ seldom wash their hands with soap and water after any direct contact with patients.

Majority of the participants recap used needles after giving injections or drawing blood from the patients $48(63.2 \%)$, while $20(26.3 \%)$ do not recap used needles after giving injections or drawing blood from the patients and $8(10.5 \%)$ remove needles from the disposal syringes after giving injections or drawing blood from the patients.

Majority of the participants use a puncture proof container when discarding used needles and sharps 36 (50\%) compared to $19(25.0 \%)$ use a closed dust bin when discarding used needles and sharps, $8(10.5 \%)$ use any available container while $9(11.8 \%)$ use a dust bin covered with plastic.

Majority of the participants always wear gloves for contact with body fluids, non-intact skin and mucous membrane $65(81.3 \%)$ compared to $10(12.5 \%)$ that often wear gloves for contact with body fluids, non-intact skin and mucous membrane and $5(6.3 \%)$ that seldom wear gloves for contact with body fluids, non-intact skin and mucous membrane.

Majority of participants always cover all cuts and abrasions with a water proof dressing when coming in contact with clients $59(75.6 \%)$ compared to $10(12.8 \%)$ that often cover all cuts and abrasions with a water proof dressing when coming in contact with clients $2(2.6 \%)$ that seldom cover all cuts and abrasions with a water proof dressing when coming in contact with clients and 7 (9.0\%) that never cover all cuts and abrasions with a water proof dressing when coming in contact with clients.

Other standard precaution practices evaluated include whether sharps disposal containers are located as close as practical to the use area $64(83.1 \%)$, if they had needle stick injury in the last three month 7 $(8.4 \%)$, if post exposure prophylaxis (PEP) is available 22 (33.8\%), awareness of guideline for PEP management $42(55.3 \%)$ and if they have been vaccinated against Hepatitis B 21(26.9\%) - Table 3.

Table 3. Frequency distribution of standard precaution practices by community pharmacists

\begin{tabular}{|l|l|l|l|}
\hline Question Items & Yes (\%) & No (\%) & Total, N (\%) \\
\hline $\begin{array}{l}\text { The sharps disposal containers } \\
\text { are located as close as } \\
\text { practical to the use area }\end{array}$ & $64(83.1)$ & $13(16.9)$ & $77(74.0)$ \\
\hline $\begin{array}{l}\text { I have had needle stick injury } \\
\text { in the last three month }\end{array}$ & $7(8.4)$ & $76(91.6)$ & $83(79.8)$ \\
\hline $\begin{array}{l}\text { Is post exposure prophylaxis } \\
\text { (PEP) available }\end{array}$ & $22(33.8)$ & $43(66.2)$ & $65(62.5)$ \\
\hline $\begin{array}{l}\text { Are you aware of guideline for } \\
\text { PEP management? }\end{array}$ & $42(55.3)$ & $34(44.7)$ & $76(73.1)$ \\
\hline $\begin{array}{l}\text { Have you been vaccinated } \\
\text { against Hepatitis B? }\end{array}$ & $21(26.9)$ & $57(73.1)$ & $78(75)$ \\
\hline
\end{tabular}

\section{Discussion}

The results obtained from this study are interesting and provide an insight into community pharmacists' knowledge of HIV/AIDS and standard precautions and their practices. There are a number of trends which are evident, some of which are not surprising, while others are rather worthy of note.

Majority of pharmacists in community practice are male and majority have only Bachelor of Pharmacy degree. Respondents have excellent knowledge of the causative agent of HIV and assigned relatively high scores to non-preventive measure of HIV/AIDS, the transmission routes of HIV and also Tuberculosis as the most common opportunistic infection in HIV-infected patients. This is expected because they are basic information about HIV/AIDS. However, majority did not know the transmission rate from mother 
to child in the absence of antiretroviral drugs in developing countries and also did not know that the chief predictor of heterosexual transmission of HIV is plasma viremia. The lack of knowledge about the transmission rate was associated with participants' level of education and years of experience and could be attributed to participants not updating their knowledge with current issues.

All the participants had valid practicing license and majority had audio-visual privacy to enable them counsel clients privately on one-on one. Most of these pharmacies do not stock antiretroviral drugs and only some of them provide services to HIV clients. This can be attributed to the fact that HIV drugs are given free to clients in the hospitals therefore are hardly bought and may expire on them causing loss. It is worthy to note that many of them have been trained on pharmaceutical care in HIV/AIDS, TB and STI.

All the pharmacies provide one or more HIV related services although not very strongly, such as HIV risk assessment and counseling, palliative care services, HTC services, TB services, and some common services that are very much provided in these pharmacies are malaria prevention, reproductive health services, malaria screening and treatment, STI treatment, provision of condoms and referral services. This is not unexpected since these activities are associated with the traditional functions of community pharmacists and since some community pharmacies in Nigeria are now used as palliative care and referral points to increase demand for HIV services in the community (Dorothy Oqua, 2011). Effective management of HIV/AIDS by community pharmacists is not dependent on their knowledge and practice of standard precaution. In general, this study has shown that the knowledge and practice of community pharmacists in HIV/AIDS management is not intense and hence agrees with the alternate hypothesis which says that effective management of HIV/AIDS by community pharmacists is dependent on their knowledge and practice of standard precaution.

The study shows that many of the community pharmacists have good knowledge of standard precaution concept and when hand washing is supposed to be performed; the level of these knowledge declines as the years of experience increased and as their level of education rose. Studies by Angelillo et al (1999) recommended that attending continuing educational modules about hospital infection had a positive effect on infection control procedures and compliance with barrier techniques (Angelillo et $a l ; 1999)$. Many of the participants indicated correctly all the potential ways of occupational exposure and becomes more significant as their years of experience and level of education increased. The knowledge of the conditions of which standard precautions should be practiced declined as the level of education rose. Education has a positive impact on retention of knowledge, attitudes and practices in all the categories of health professionals hence, there is a need to develop a system of continuous education for all the categories of health professionals (Suchitra J B and Lakshmi Devi N; 2007). Few of the respondents reported correctly that for HIV post exposure prophylaxis (PEP), HIV counseling \& testing is done immediately after the exposure and PEP is given only to HIV negative test result conditions.

In answering questions relating to the practice of standard precaution, only $50 \%$ use a puncture proof container when discarding used needles and sharps and 63.2\% recap used needles after giving injections or drawing blood from the patients and when compared with their level of education and their years of experience, the practice of standard precaution declined as the years of experience increased and as level of education rose which may be that the respondents in the course of their practice became careless in their practice regarding standard precaution. This therefore, agrees with the hypothesis that 'Effective management of HIV/AIDS by community pharmacists is not dependent on their knowledge and practice of standard precaution'. Although there has been controversy about how much HIV transmission in Africa is due to healthcare practices (Gisselquist D, Potterat JJ. 2004, Schmid GP et al; 2004), eliminating all unsafe practices in health facilities should be an urgent priority for HIV prevention and for overall infection control.

The fact that a significant proportion practice standard precaution by always wearing gloves for contact with body fluids, non-intact skin and mucous membrane shows that wearing gloves is an important line of defense. Majority of participants always cover all cuts and abrasions with a water proof dressing when coming in contact with clients and have their sharps disposal containers are located as close as practical to 
the use area however majority of the respondents do not have post exposure prophylaxis available and have not been vaccinated against Hepatitis B. Inadequate knowledge and unawareness of guideline for PEP management as well as unavailability of Hepatitis B vaccine may have contributed to these unsafe practices. Only $8.6 \%$ have had needle stick injury in the last three months.

\section{Conclusion}

This study findings showed that the knowledge and practice of community pharmacists in HIV/AIDS is somewhat poor. Although the knowledge of community pharmacists on standard precaution was good, there were deficiencies in their practice of standard precaution especially in the area of handling and disposal of used needles, availability of post exposure prophylaxis and vaccination against Hepatitis B. Therefore, the null hypothesis which says that effective management of HIV/AIDS by community pharmacists is independent on their knowledge and practice of standard precaution is sustained. HIV/AIDS should be integrated into the curriculum for continuing professional development of pharmacists. The enforcement of adherence to the principles of standard precaution through regular monitoring and supervision is highly advocated.

\section{References}

[1]. Adinma ED1, Ezeama C, Adinma JI, Asuzu MC. Knowledge and practice of universal precautions against blood borne pathogens amongst house officers and nurses in tertiary health institutions in Southeast Nigeria. Niger J ClinPract. 2009 Dec;12(4):398-402

[2]. Aisien AO, Shobowale MO Health care workers' knowledge on HIV and AIDS: universal precautions and attitude towards PLWHA in Benin-City, Nigeria. PMID:16477857) Nigerian Journal of Clinical Practice [2005, 8(2):74-82].

[3]. Angelillo IF, Mazziota A, Nicotera G. Nurses and hospital infection control: Knowledge, attitudes and behavior of Italian operating theater staff. J Hosp Infect 1999; 42:105 -12

[4]. Chan R, Molassiootis A, Chan E, Chan V, Ho B, Lai CY, et al. Nurses' knowledge of and compliance with universal precaution in an acute care hospital. Int J Nurs Stud 2002;39: 157-63.

[5]. Delobelle $\mathrm{P}^{1}$, Rawlinson JL, Ntuli S, Malatsi I, Decock R, Depoorter AM HIV/AIDS knowledge, attitudes, practices and perceptions of rural nurses in South Africa. J Adv Nurs. 2009 May;65(5):1061-73

[6]. Dorothy Oqua, Rosalyn King, Uford Inyang, Kufre Okop, Chamberlin Onuoha, Habeeb Abdulkareem, Kenneth Agu and Ahmad Abubakar "Community Pharmacies as Palliative Care and Referral Points to Increase Demand for HIV Services in the Communities" Howard University PACE/GHAIN Nigeria, October 2011.

[7]. Garbus L. HIV and AIDS in Malawi: Country AIDS policy analysis project. San Francisco, CA: Policy Research Center, University of California San Francisco; 2003.

[8]. Gisselquist D, Potterat JJ. Review of evidence from risk factor analyses associating HIV infection in African adults with medical injections and multiple sexual partners. Int J STD AIDS 2004; 15:222-33

[9]. Hentgen $\mathrm{V}^{1}$, Jaureguiberry S, Ramiliarisoa A, Andrianantoandro V, Belec M. Knowledge, attitude and practices of health personnel with regard to HIV/AIDS in Tamatave (Madagascar) Bull Soc Pathol Exot. 2002 Jun;95(2):103-8.

[10]. Hirsch JD, Rosenquist A, Best BM, et al. Evaluation of the first year of a pilot program in community pharmacy: HIV/AIDS medication therapy management for Medi-Cal beneficiaries. J Manag Care Pharm. 2009;15(1):32-41. [PubMed]

[11]. Horn W A, Larson EL, McGinley KJ, Leyden JJ. Microbial Flora on the hands of health care personnel: Differences in composition and antibacterial resistance. Infect Control Hosp Epidemiol 1988; 9:189-93.

[12]. Isara AR1, Ofili AN. Knowledge and practice of standard precautions among health care workers in the Federal Medical Centre, Asaba, Delta State, Nigeria.Niger Postgrad Med J. 2010 Sep;17(3):204-9

[13]. Mbanya DN, Zebaze R, Kengne AP, Minkoulou EM, Awah P. Beure Knowledge, attitudes and practices of nursing staff in a rural hospital of Cameroon: How much does the health care provider know about the human immunodeficiency virus/acquired immune deficiency syndrome? IntNurs Rev 2001; 48:241-9.

[14]. Michael Thompson, The consultant Pharmacist; 1999 
DOI: 10.21522/TIJPH.2013.SE.19.01.Art016

ISSN: 2520-3134

[15]. Okike O, Jeremiah I, Akani C (2011). Knowledge, Attitude and Practice of General Medical Practioners in Port Harcourt towards Prevention of Mother to Child Transmission of HIV. Nig. Health J. 3:79-82

[16]. Pharmaceutical Journal, 'Dealing with accidents in the pharmacy' 2011; 286:69-70.

[17]. Physicians for Human Rights (2006) 'Nigeria: Access to Health Care for People Living with HIV and AIDS'

[18]. Sadoh WE, Fawole AO, Sadoh AE, Oladimeji AO, Sotiloye OS. Practice of universal precautions among healthcare workers. J Natl Med Assoc 2006; 98:722-6.

[19]. Shiao J, Guo L, McLaws ML. Estimation of the risk of blood borne pathogens to health care workers after a needlestick injury in Taiwan. Am J Infect Control 2002; 30:15-20

[20]. Talashek ML, Kaponda CP, Jere DL, Kafulafula U, Mbeba MM, McCreary LL, et al. Identifying what rural health workers in Malawi need to become HIV prevention leaders. J Assoc Nurses AIDS Care 2007;18:41-50.

[21]. UNAIDS 2017, available at http://www.unaids.org/en/regionscountries/countries/nigeria. Accessed 23 December 2018

[22]. Van Niekerk A. and Loretta M. Kopelman. Ethics \& AIDS in Africa: The Challenge to Our Thinking. Walnut Creek, CA: Left Coast, 2005.

[23]. Worker Health Chart book 2004. Blood borne Infections and Percutaneous Exposures DHHS (NIOSH) Publication No; 2004. p. 146.

[24]. Suchitra J B, Lakshmi Devi N. Impact of education on knowledge, attitudes and practices among various categories of health care workers on nosocomial infections. Indian J Med Microbiol [serial online] 2007 [cited 2014 Apr 3]; 25:181-7. Available from: http://www.ijmm.org/text.asp?2007/25/3/181/34757 